\title{
Exploring the Challenges Faced By Indian Military Wives during Spousal Deployment/ Field Area Posting
}

\author{
Dr. Priyanka Misra ${ }^{1} *$
}

\section{ABSTRACT}

The purpose of this study was to explore the deployment experience of Indian military wives and to gain insight about the stressors faced by them during the deployment of their spouses and how they coped with these challenges. In-depth interviews were conducted with 25 military wives to get a deeper understanding of their lives. Thematic analysis of the interviews revealed stressors related to relocation, household hassles and single parenting. Critical events occurring along with these challenges added to the separation woes creating a pile up of stressors. Confronting by acting/listing/postponing, keeping busy to avoid negative emotions, self-care, positive self-talk and praying were a few coping methods employed by the wives.

Keywords: Challenges, deployment, Indian military wives, coping methods

Since its inception in 1947 , the primary responsibility of the Indian military has been to safeguard the territorial integrity of the nation against external aggression. Given the long borders of the Indian mainland with different geographic and climatic conditions, and the not so congenial neighborhood constant vigilance and alertness is required apart from continuous training to meet the diverse challenges. Since independence the Indian military has been involved in four wars with the neighboring Pakistan and one with People's Republic of China. Incursions, infiltration and frequent ceasefire violations from across the border keeps the armed forces on its toes. The result is prolonged and multiple deployment of the service members along the borders to keep a check on the hostile neighborhood. The Indian Army has also been exposed to Low Intensity Conflict/ Terrorism or Militancy since the 1960's. Since then, new areas of conflict have emerged every decade with more and more troops getting involved. Nearly $45 \%$ of the deployable army is posted in field areas at any given time and for an Indian soldier a field area tenure/ deployment may last for duration of 24 to 30 months. In peace stations, the deployment may be due to internal disturbances or natural calamities where the duration of deployment depends on the exigencies of the situation. Besides this, the army conducts exercises every consecutive year which may last for a period of 3 months.

${ }^{1}$ Counselling Psychologist, Institute for Development Research and Action (InDRA) Allahabad, India *Responding Author

Received: July 16, 2019; Revision Received: September 21, 2019; Accepted: September 26, 2019

(C) 2019, P Misra; licensee IJIP. This is an Open Access Research distributed under the terms of the Creative Commons Attribution License (www.creativecommons.org/licenses/by/2.0), which permits unrestricted use, distribution, and reproduction in any Medium, provided the original work is properly cited. 


\section{Exploring the Challenges Faced By Indian Military Wives during Spousal Deployment/ Field Area Posting}

Apart from these internal conflicts, the Indian Armed forces have also been mandated to contribute to United Nations peacekeeping missions since its inception in 1950 to maintain peace and assist in various humanitarian operations. So far, Indian troops have taken part in 43 Peacekeeping missions in various parts of the world with a total contribution exceeding 1 , 60,000 troops. The duration of UN Mission deployment is 6 months to 1 year.

Military psychological research shows us that a period of separation takes the third place in the list of stressful events, only preceded by death of a partner or divorce (Holmes \&Rahe, 1967). Long term separations resulting from serving in combat zones or difficult terrains can be traumatic not only for service members but also their families. A number of studies have been done in the west to assess the impact of deployment on military spouses. Families experience stress, before, during and after deployment. Emotional turmoil related to the impending field posting starts from the first hint of movement of the soldier to field areas. Lack of direct and frequent communication, restricted access to such areas, prolonged separation, challenges of daily living puts the families under considerable amount of pressure. Studies have shown that military-induced separations create stress due to the commotion accompanying departure, increased caretaking and household responsibilities, disconnected relationships, loss of emotional support, and the readjustment of roles upon reunion. Military deployment creates high levels of strain for spouses who remain at home (Peebles-Kleiger \& Kleiger, 1994). Spouses left at home face financial challenges, loneliness and additional parenting responsibilities. Military spouses become single parents during deployment, leaving them with total responsibility of the household and children, changing family dynamics, and financial strain (Beard et. al, 2008). Compounded by the absence of relationship partners and the worry of spousal injury or death (Beard et al., 2008), the challenges military spouses face are sizeable and the impact they can have is significant. Studies report higher levels of depression following spousal deployment (Jensen et al., 1996) along with feelings of abandonment, uncontrollability, and conscious or unconscious rage (Peebles-Kleiger \& Kleiger, 1994).

Most army families experience annual duty-related separations, and military spouses report that separations are their greatest source of dissatisfaction with military life (Black, 1993). Deployment induced separations produces changes and challenges for individuals within the family, and these challenges can cause psychological problems. Yet it has also been seen that military families manage to effectively cope with deployment and the losses and struggles incorporated within it. The interactional definition of stress presented by Lazarus and Folkman (1984) is of relevance to this research. According to them, stress occurs when there are demands on a person that tax or exceed his adaptive resources. Stress is defined as arising from "the relationship between the person and the environment, which takes into account characteristics of the person on the one hand, and the nature of the environmental event on the other" (Lazarus \& Folkman, 1984). Cognitive appraisal is seen as the critical concept explaining the judgment that a particular person-environment relationship is stressful. It is thus viewed as the central mediator or process variable in a "cognitive theory of stress." The other major process or mediator variable identified by Lazarus and Folkman (1984) is "coping." Coping is defined as "constantly changing cognitive and behavioral efforts to manage specific external and/or internal demands that are appraised as taxing or exceeding the resources of the person". Mostly military families have been found to be able to live up to the challenges and develop into resilient families. 


\section{Exploring the Challenges Faced By Indian Military Wives during Spousal Deployment/ Field Area Posting}

Despite the fact that Indian military families have for long been exposed to wartime/ combat and routine deployments for at least five decades, their circumstances and challenges and how they cope with them, has mostly gone unnoticed. In stark contrast to the plethora of western literature on combat-related stress and its consequences for military personnel and their families, only sparse Indian works exists. The stresses and challenges faced by military families due to deployment induced separation have received little recognition as a problem area for research. As long as Low Intensity Conflicts persist, these deployment challenges will not disappear. The purpose of this study was to explore the problems and challenges faced by the military wives during their husband's deployment and also to gain an understanding of their coping methods.

\section{METHODOLOGY}

\section{Sample}

25 military wives whose partners were deployed in field areas or non-family stations of the north and the north-east or were deployed overseas as a part of the UN peace keeping Force were included in the study on the basis of snowball sampling. Some women were experiencing their first spousal deployment, whereas, other women were on their second, third or fourth spousal deployment $(\mathrm{M}=2.2)$. The age of these women ranged from 27 to 40 years $(M=30.6 \mathrm{yrs})$. The duration of marriage between partners ranged from approximately 11 months to 22 years $(M=10.25)$. The number of children ranged from 1 to $4(M=2)$ with all of the women having at least one child. Care was taken to recruit wives of all ranks of service members. Total of 13 women interviewed were wives of service members belonging to Persons below Officer Rank (PBOR). 12 women were wives of Commissioned Officers.

\section{Method}

For the current study, 25 in-depth interviews were conducted face-to-face. Interviews were conducted at the participants' homes in Field Area Family Accommodations in Allahabad cantonment. Many of the participants were willing to be a part of the study after hearing about it from their friends and acquaintances.

\section{Measures used}

1. What are the problems that you face when your husband is deployed?

1. In Daily life

2. As a parent

2. What are the most-difficult things about deployment?

3. How do you deal with the challenges?

\section{Procedure}

The interviews were initiated with an introduction of the interviewer and a brief account of the purpose of the study. All participants were informed of measures taken to protect confidentiality. The interviews were recorded after the participants gave consent for the same. Interviews lasted between 50 minutes to 125 minutes $(M=94.9)$, and participants were given the option to stop the interviews or take breaks to attend to their chores as needed. Semistructured interview were utilized, which allowed to the researcher to begin with a broad set of questions and probe for additional information in a more spontaneous manner. 


\section{Exploring the Challenges Faced By Indian Military Wives during Spousal Deployment/ Field Area \\ Posting}

\section{Analysis}

Upon gathering data, all interviews were transcribed verbatim. Once interviews were transcribed, a thematic analysis of the data was done. This type of analysis refers to the "qualitative data reduction and sense making effort that takes a volume of qualitative material and attempts to identify core consistencies and meanings" (Patton, 2002). Locating interpreting and defining the themes was done using constant comparative analysis (Strauss, 1987; Strauss \& Corbin, 1990). For the purpose of presenting the data in written form, some translation was done since all the interviews were in Hindi. Care was taken to retain the sense of the language as closely as possible. In cases where a satisfactory translation was not available, the original language of the narrative has been retained. These themes and sub themes were checked by fellow researchers to establish inter - coder reliability.

\section{RESULT}

Result of this study is divided in two sections. In the first section all the stressors and challenges faced by the wives of deployed army personnel are explored which is further explained at three levels. In the second section, coping methods are listed and described.

\section{SECTION ONE: Stressors and challenges \\ Relocation}

Deployments are stressful not only because of the impending separation but also because of the huge and almost immediate transitions it brings along for the entire family, relocation being one of them. There are major decisions to be made by the family, the most important being where will they be staying during this period which may last from 18 months to 3 years. Some families choose to stay back in the same station shifting to the Field Area Family Accommodations (FAFA) provided by the military within the cantonment. Others may choose for FAFA in or near their native places where they have friends and family. Still others go back home to stay with their parents or in-laws during the field posting of their husband.

When asked about challenges wives mentioned 'shifting, relocating, deciding where to stay' as issues that bothered them. A change of place is definitely in order within the first three months after the field area posting is declared. From the narrations of the respondents it is clear that they are very well aware of the pros and cons of any choice. The military wives interviewed had gone through deployments earlier and they felt staying within the cantonment was better than going back to in laws or parents' place for several reasons,

'You are under so much pressure at your parents' place'

'When husband is not there with you, you are just a servant of the family members at in laws place"

Other factors were availability of services and resources like the Military hospital, Army school, etc., children's education, better schooling opportunities, safe and secure environment away from the rural atmosphere where wives felt 'they (children) get spoilt there. A village is after all a village only'.

While for some families, the choice of FAFA is natural, for others it is dependent on the 'husband's whims' as one wife chose to call it. They also hinted that things were not that 


\section{Exploring the Challenges Faced By Indian Military Wives during Spousal Deployment/ Field Area \\ Posting}

simple and that it was mainly the husband who decided about where they could stay. As one wife said,

'It all depends on the husband. If he wishes, he can keep you in SF. If not then you have to go back to in- laws'.

\section{Household Hassles}

During deployment women become the sole executors of the household chores and they are left alone to do everything on their own. The absence of the husband left the wives overburdened with too many responsibilities. They often felt overwhelmed with the tasks and decisions feeling often that it would be easier if they just had their husbands at home to share the responsibilities.

Household hassles expressed by wives were basically of the nature of either role overload or daily hassles.

\section{Work/ Role Overload}

The wives began by talking about having too many responsibilities like having 'to do all indoor and outdoor household work', 'trouble in keeping the lawn clean' 'maintaining the car' and 'getting broken household items repaired' when asked about the problems they experienced during their husband's absence. Several wives noted that household maintenance issues were a significant challenge, especially, when one had to take over the work which was done by the husband earlier.

"Now I feel all this is too much to handle."

Elaborating upon the range of responsibilities a wife said,

"Kids, in laws....all are dependent on me. Sending the kids to school, teaching them, getting stuff for the household, and going for MES complaints...... everything you have to do on your own."

Wives also felt making decisions on all major and minor family issues could get stressful at times because they were not used to it. Most of the major decisions, wives said, were either taken jointly by them or by the husband. Deciding about daily affairs of running the house became overwhelming initially but gradually they settled down and started liking it. However, decisions about kids' education, schooling, tuitions and coaching continued to bother them for the entire duration of separation.

'Throughout the day I am making one or the other decision. What is to be done how, it has to be done? What all should I share with him and what I should withhold'?

Women related their experience and challenges to being single mothers.

"Having to manage everything by myself basically... Then dealing with other things, sometimes I feel so bored and even depressed, I don't do anything. I just feel like sitting and sulking. But you know there are kids, they never let you be. You have to always be in control." 


\section{Exploring the Challenges Faced By Indian Military Wives during Spousal Deployment/ Field Area \\ Posting}

\section{Daily hassles}

Petty annoyances, frustrations, and unpleasant surprises we experience every day may add up to more grief than life's major stressful events. Those circumstances which were non issues earlier became annoyances in the husband's absence. Some of the hassles wives experienced related to the MES (Military Engineering Services) and its functioning, commuting problems, running around in the $\mathrm{MH}$ alone and financial problems.

Relating her woes with the MES, that is responsible for the maintenance of the houses in the cantonment, an Army officer's wife said,

"I have the phone number not only of the GE but also the JE, the contractor and even the Munshi who actually supervises the work on ground. Just going there and writing the complaint does not help. The minor ones do get attended to but if there is a little more work, then you keep running around. No wonder the houses are in such a poor condition."

Some wives reported commuting as a problem due to non-availability of vehicles (rickshaws/ autos) within the cantonment. This was a problem related by mostly the wives of the lower ranks,

i.e. the PBOR. The unavailability of one's own mode of transport left wives 'tied down and tired at times.' Expressed one wife,

"Going out is a problem. There is no vehicle and we don't easily get rickshaws in the cantonment."

Few wives also mentioned having to entertain guests and relatives who come over to stay as being stressful.

'If some relatives come then I face many problems ... whether to look after them or my children'.

If there are relatives who come and also help then it is okay. Otherwise it is difficult to look after them. Alone, you are not able to look after yourself. How are you going to take care of them?'

The financial problems discussed by the wives were mainly of two types. One aspect involved the managing of finances singlehandedly. Some wives talked about the pressure of handling family finances and expenditure alone.

"I do not have to use my brain about expenses and budget when we are together. Now I have to do all the planning myself."

A few wives mentioned experiencing financial constraint, because husband could not remit money in time or because there was some monetary dispute with the extended family. Recalling an incident when there was no pressure of having a joint account and husband used to send money by hand a wife said,

'Sometimes I feel he used to deliberately delay sending the money just to show his control. Now it is compulsory for everyone to have a joint account'. 


\section{Exploring the Challenges Faced By Indian Military Wives during Spousal Deployment/ Field Area \\ Posting}

Some wives mentioned having problems in withdrawing money from the ATMs while still others felt that it helped avoid the unnecessary strain of going to the bank. Three women in the sample had problems using the ATM. Said one wife,

'I can't use ATM. My husband either sends cash money or he gives me cheques. He fills the amount and signs it before leaving. Sometimes he forgets then there is a problem. I send my daughter to withdraw money from ATM. I can't.

Wives also stated that contrary to the popular perception that field area postings result in financial gains, there was an increase in family expenses. Said one wife,

'You have two set ups to manage now. Husband also spends money, the mess bill and the phone bills. If you have an army phone then it is okay otherwise phone bills increase on both sides'.

Another wife pointed out, 'When husband comes on leave then also expenses increases. We spend a lot more when he comes on leave. Kids also feel very secure...there are more toys more games, new things, more outings, more eating out'.

'There are two set ups so there are no savings', confirmed another wife. Explaining how finances are affected another wife said, "He keeps overspending. Actually all savings get exhausted when he comes on leave, bringing so many things for the house, gifts for the others in the family, you ask for one thing and he brings ten. Not a penny is saved."

The military wives talked about a whole range of household problems experienced by them on a daily basis during deployment. From having too many responsibilities, to not having anybody to help, the participants talked in detail about the house hold hassles and difficulties they faced on a day to day basis in the running of the house.

\section{Single Parenting stress}

Military wives expressed several concerns regarding their children in the absence of their father. It was also noticed that with different age groups of children the hassles as well as the anxieties of the mothers were different. While the fears and anxieties expressed by the military wives may be seen as being common to all mothers in general, the pressure of handling it all alone left them particularly stressed out. Parenting stress here refers to the specific issues and concerns mothers/wives expressed about the children which caused distress in the husbands' absence. Three major types of concerns were expressed by the wives. One has been named nurturing challenges referring to the enhanced dual role women had to play to compensate for the fathers' absence besides care giving. The second concern expressed by the wives was regarding the behavioural changes they noticed in their children because of which they had to change their parenting style. The third was the children's education; their school performance, problems in school and other education related decisions.

\section{The Dual role-Nurturing and disciplinarian}

Without their husbands around, these women become single mothers and they no longer had their husband's helpful backup and complementary actions. Mothers felt that their husbands offered a different role for their kids; they played and they also punished. While women 


\section{Exploring the Challenges Faced By Indian Military Wives during Spousal Deployment/ Field Area \\ Posting}

played the nurturing role their husbands were the disciplinarians. Emphasizing these changes and challenges, and the struggle to balance 'mother' and 'father' roles a wife said,

"Only mother is there. I am the one who is scolding and then sympathizing also.... Everything is dependent on one person. The kids also understand. They know that mummy will come around after some time."

Mothers with very young kids found themselves struggling between their role as the nurturer and other responsibilities,

'My husband does not do much as far as looking after the kids is concerned, ....but at least he runs those last minute errands like bringing pencil and paints and other such things which children tell at nine clock in the night'.

Mothers also discussed that they had no down time to recover because they were constantly tending to the children and the home. One mother shared,

'Looking after the baby alone all the time, I get frustrated. Sometimes I just want a little time for myself.'

Similar were the travails of mothers with older children. The only noticeable change was in the nature of responsibilities.

'You are the sole care taker of the kids, so you look after their studies and keep an eye on their friendships and their activities outside as well as inside. When husband is there you have some support. It is only your pressure now. If nothing at least he calms me down if I take too much stress'.

Women also noted that they had to be extra careful so that the children do not miss their father which put additional burden on their nurturing responsibilities.

I have to take care that they do not miss out any activities since their dad is not here. It is a kind of pressure actually. Sometimes they complain, you know....like they say we don't go anywhere, why don't you take us out like others and so on. Then you feel bad for the kids'. 'Children should not suffer.... They should not feel that papa is not here.'

\section{Behavioural changes / Challenges}

Yet another parenting challenge women had to face was the behavioural changes in their children during father's field posting. This problem was predominant in mothers with adolescent children.

Women expressed that children of this age group particularly needed the firmness of their father.

I have to keep shouting at them to study. Even for some work I have to instruct them several times. They don't listen. With their father, they listen immediately. No second call is required'.

'I think they learn to defy you in the absence of the father." 


\section{Exploring the Challenges Faced By Indian Military Wives during Spousal Deployment/ Field Area \\ Posting}

Other mothers also noted change in behaviour in the children. They felt that children respond in different ways to the same situation. For instance, one mother found differences in the way each of her child's behaviour changed during their father's absence. While her son became more 'outgoing', she noticed a more 'introverted and withdrawn' behaviour in her daughter. Mothers expressed concern about their children's activities, especially boys as they showed 'increased aggressiveness', 'lack of interest in studies, spending more time with friends outside and an increased tendency to engage in fights outside'.

Women felt that children understood their limitations as single parent and got the message that they can get away with anything. They also emphasized the need for constant vigilance.

'You have to be very discreet with the kids. All the time you have to keep an eye on them. The children become fearless (bacchon mein nidarta aa jaati hai) They feel papa is not there, now they can do anything. You can't pressurize them too much."

As a consequence of being a single parent women also noted a change in their parenting style. 'My kids don't bother me much. But I have to be strict with them. I can't afford to be lenient..."

\section{Concern about Education / School Performance}

Many mothers especially those who were less educated, belonged to rural background worried about the education of the children. Their prime concern was that the absence of the father had a negative impact on the academic performance of the children,

'Since their father is not here, they tend to take their studies very lightly.

'My son studies only when his dad is around. My daughter is sincere but my son needs his father's strictness'.

Similarly some wives mentioned problem 'in getting the homework done', 'attending parent's teacher meeting' and 'helping with school projects' as being too much to handle along with the household chores.

\section{Critical events}

The presence of further challenges, in addition to the stress of deployment can place families at significant risk. While discussing the problems they experienced during deployment, military wives also elucidated upon other critical events which had occurred during their separation period and which had troubled them deeply. Some additional challenges that have emerged in the interviews are, one's own ill health, pregnancy, having a family member dealing with long term illness, death of closerelative/family member, high levels of family conflict and poor communication between family members.

\section{Prolonged illness/death of a family member}

Nine out of the 25 women interviewed mentioned looking after an ailing family member during husband's deployment as an acute source of stress. Talking about their care giving experiences, they became emotional. Besides the nursing and the looking after, what bothered them most was that the children got neglected in the process. 


\section{Exploring the Challenges Faced By Indian Military Wives during Spousal Deployment/ Field Area Posting}

I bore the family burden. My in-laws stayed with me. I had called them for treatment when my father in law was ill. He had cancer and later paralysis. I stayed with him in the MH for a month. Walking to and fro from the hospital drained me completely. Later the doctors sent him back because they couldn't do anything further. I have done everything for him, bathing, feeding, washing... despite being a daughter in law. I had to. My mother in law is so frail. Also he was 6 feet something. It was difficult ...but there was no option. He passed away in January. My husband could reach only after three days. I had to make the decision of his cremation. I decided to do it the same day and not wait for my husband. It was big thing for me. In a military family, the daughter in law is the son. There is a lot of frustration in me. I used to think they are his (husband's) mom and dad and I am the one who is suffering'.

\section{Housing problem}

Another major and common source of stress which emerged was housing related problems. Due to shortage of government accommodations, families who are not willing or do not have an option of going back to their native place have to stay in rented houses in civil areas. The waiting period reported could be anything from a month to about a year in some prime stations. Condition of the allotted house was also mentioned by wives as the stressor. Seepage in the house was a complaint made by at least 13 out of the 25 families. Other than that wives expressed dissatisfaction at the size of the house. Garage sharing was another problem mentioned by the military wives as they complained about housing woes.

\section{Personal Ill- Health}

Research on the impact of deployment on spouses suggests the stress that accompanies deployment may undermine spouse's psychological and physical well-being. At the same time it can also be said that ill health and specific physical conditions like pregnancy can aggravate the stress due to deployment induced separation. Pregnancy and one's own ill health are two factors which emerged as additional stressful experiences from the narratives of the military wives. Pregnant wives reported 'missing their husbands' pampering and togetherness at such crucial stage of life', wives who had suffered miscarriage or had chosen abortion described it as 'a traumatising experience' and wives who had health issues felt that it had a compounding effect on their already stressful lives. They specifically expressed concern about their children because there would be no one to look after them when ill health took on them.

\section{Concerns Related to the Deployed Spouse}

Spousal concerns include issues related to one's spouse as he served in a formal, hierarchical organization in hostile environment and inhospitable terrains away from the family. The military wives discussed the problem of their husbands not getting leave as per requirement, worrying about their wellbeing depending upon the nature of field posting, inability to communicate and trust issues in a long distance relationship.

Real time media coverage of combat operations added to the distress of the wives,

'When husband is in CI then there is a lot of tension. These days they show so much on TV. Some days each hour is difficult to pass by. Children also are now grown up enough to understand what is going on'.

Wives also discussed two other stressors, the inability to communicate due to network problems and trust issues which were causes of concern for them.

(c) The International Journal of Indian Psychology, ISSN 2348-5396 (e)| ISSN: 2349-3429 (p) | 396 


\section{Exploring the Challenges Faced By Indian Military Wives during Spousal Deployment/ Field Area \\ Posting}

\section{Family Disputes}

Conflict with other members of the extended family over property related matters, and financial disputes were also reported by families as being stressful events during husband's absence. It becomes a complex situation when a wife chooses to stay separately and the soldier has to provide not only for his own family but also for his parents and siblings. While the husband is posted away it is the wife, who has to bear the brunt of in-laws wrath which may be in the form sarcastic remarks on phone, or by not talking at all.

'They make sarcastic comments. Now how should I explain to them that here too there is a kitchen functioning, there is a house...kids go to school. Nobody says anything to him (husband).he is the son. He can't be wrong.... am the one who must have spoilt him. Every time I talk to them, they upset me'.

Finances emerged as a major source of conflict with

'They think if he is earning why he is not giving money.'

\section{Social Withdrawal /Burden}

While women did accept that they forge new bonds, make new friendships, they also felt that socially they tend to withdraw and were less keen on sustaining personal relationships during deployment.

'I generally avoid going out when my husband is away and people understand if they want to. Even at marriage parties and family get together, I don't feel like going. After some time you start feeling everybody is together, complete family types and here I am alone', explained another wife.

Critical events were those occurrences which wives had reported to be particularly distressing when husband was away. These are a few of the common situations which wives had faced and which many of the wives identified with.

\section{Section Two: Coping}

Faced with the ups and downs of separation due to field area posting/ deployment and diverse experiences, these women had only one option- to deal with the changes and challenges. Most women found coping mechanisms and supportive resources that helped them to overcome or at least live with their experiences because they had lives to live and families to sustain.

\section{Listing/Acting/ Postponing}

In order to cope with the range of demands military wives resorted to strategies like making a 'to do list', acting on some of things that they found feasible and postponing others for a later time. Most families are traditional families where husbands are breadwinners and also responsible for a large chunk of outdoor household work while the women looked after the internal affairs.

Wives going through first separation or those who were staying independently away from the extended family for the first time, wives of lower ranks were particularly overwhelmed with the enormity of the tasks they had before them. One strategy adopted by women was to make a list of outdoor work to be done and then attend to the most important ones. 


\section{Exploring the Challenges Faced By Indian Military Wives during Spousal Deployment/ Field Area Posting}

I make a list of all the outside work and I go out one day to do all the shopping and pending work. For many days I would cry a lot. I am a village woman used to living in purdah. I do not want to go out every day. It is tiring. When enough work gets accumulated then I go out. If it is very important then only I do it.'

Postponing was another strategy,

'I do whatever I can. Mostly I leave things pending or postpone for some other time. I leave it for my husband to attend to the when he comes on leave'.

Some wives believed in finding their way and working to resolve the problems they encountered:

'Initially I was hesitant, going there again and again. I used to wait for my husband to come on leave to get work done but now I have learnt my way..... I manage now'

\section{Keeping Busy to avoid Negative Emotions}

Keeping busy and finding ways to distract themselves were among the most common coping strategies. Wives mentioned that keeping busy helped them avoid sitting around and worrying, waiting for their husbands to call and thinking about other unpleasant things. Watching TV, internet surfing, spending time with friends, eating out and relaxing were few other methods noted by wives to distract themselves. Many wives choose to pick up a job and pursue their hobbies to keep themselves busy.

\section{Self-Care}

Another coping strategy which might contribute to ones' attempts to keep busy, involved engaging in self care activities. Some such activities wives mentioned were 'going to gym, 'doing yoga', 'learning meditation', learning alternative healing practice like 'reiki', and 'acupressure'. They engaged in a variety of helpful behaviors such as eating healthy, reading, writing and setting some goals for themselves. Women discussed reading books and writing as a coping strategy. Developing goals such as 'to pursue higher studies', 'to do a fashion designing course' and 'doing distance education courses' were described as ways to enhance oneself.

Self-care activities served several purposes. In some cases it served as an outlet for expressing the negative emotion experienced during deployment. It also offered women something they can control in an otherwise uncontrollable situation. They could control their activities, goals, fitness, behaviors to maintain personal efficiency. Another latent purpose that engaging in self-care behavior served was that rather than just distracting, it helped in reframing and revising the deployment experience from an entirely negative one to having positive gains as well.

\section{Seeking Support}

Talking to people and seeking support from friends, family and husband emerged as prominent personal coping strategy. Women highlighted the importance of 'having people around who you can rely on'. It was noted that women often reported staying social, or talking to people and seeking support from friends, family and husbands as a prominent coping strategy for dealing with deployment. Seeking support from others in many forms was a prominent coping strategy women engaged in, although, there were some who considered themselves as sole navigators. 


\section{Exploring the Challenges Faced By Indian Military Wives during Spousal Deployment/ Field Area \\ Posting}

\section{Positive self-talk}

Wives also made efforts to maintain optimistic feelings by looking at the positive side of things, for instance, how they have managed successfully through past deployments. Thinking about their prior experience with deployment in an affirmative light helped military wives cope with their present situations. Seeking the brighter side of their present situations was also a successful and a prominent coping strategy among wives. Positive affirmations not only helped wives in adopting a self-reliant coping strategy but they also helped to manage emotions like fear and uncertainty. Positive self-talks helped in making psychological shifts to lessen the hardships of deployment. The process of maintaining a positive attitude and accepting and redirecting negative thoughts and emotions, was commonly emphasized as a helpful way of coping with deployment.

\section{Religious / Spiritual Coping}

Religious beliefs and practices influence both appraisals as well as coping with stress, as is evident from Indian as well as western studies. Military wives, especially those whose husbands were deployed in combat / operational areas, sought consolation in their religion and spirituality to cope with feelings of uncertainty and fear.

"In SF one keeps remembering God all the time....all the time praying and wishing for the field posting to pass off peacefully."

Recalling how prayers have helped her through the difficult field area postings another wife related,

'I have continued to pray. This is his last tenure in the army. He is going on pension after this. So far so good. God has helped all these years.'

When distressed by others' stories and circumstances, women relied on the notion of 'bhaagya' or destiny. 'Bhaagya' was seen as destiny or fate which was beyond their control as opposed to the notion of 'karmaphal' where the incidents in one's life are regarded as consequences of one's actions in the past or present birth.

\section{'Everyone has a destiny. Even prayers can't change one's destiny.'}

The stress buffering effect of religious coping was evident. Acceptance was used as a strategy to overcome imagined fears and anxieties regarding the deployed spouse. This helped them to deal with the stress associated with separation during field posting. Moreover, it provided them a framework with the help of which they could make sense of what had happened to others. At the same time, it is a frame of reference for interpreting and evaluating events as well as a resource to fall back upon in times of crisis.

\section{DISCUSSION}

This study focused on exploring the stressors and challenges faced by military wives during the period of actual deployment and to identify their efforts to manage their stress.

Discussing the stressors experienced by the wives, problems related to managing the household affairs alone emerged as a major source of stress. Military wives' problems revolved around two kinds of household hassles, one basically centred around having too many things to take care of which was indicative of work or role overload and the second, related to the attending the daily hassles like commuting problems, financial constraints, 


\section{Exploring the Challenges Faced By Indian Military Wives during Spousal Deployment/ Field Area Posting}

utilising banking and ATM services, problems related to children (ill-health, admission in school, coaching etc) making house maintenance complaints, booking cooking gas cylinder etc. A number of studies have found that additional household management obligations (e.g. managing finances, parenting alone) are significant sources of stress and impaired family functioning during deployment (Castaneda et al., 2008; Chandra, Burns, Tanielian, Jaycox, \& Scott, 2008; Lara-Cinisomo et al., 2012; Warner, Appenzeller, Warner, \&Grieger, 2009). Consistent with the findings in this study, a qualitative study by Castaneda and colleagues (2008) showed that household responsibilities were one of the top three deployment-related concerns for Guard/Reservists and their spouses. The spouses expressed a consistent theme of having to do everything alone while their spouse was deployed (Wheeler \& Stone, 2010). Other wives of National Guard and Reserve service members with parenting responsibilities indicate that their specific stressors during deployment were financial difficulties with bills, taking care of the house alone, and never getting a break from taking care of the children (Lapp et al., 2010)

The stress of single parenting was yet another issue which military wives talked at length about. Their concerns were about the dual role that they had to play for the children of being the nurturer as well as the disciplinarian. The wives felt that because of the behaviour changes and challenges especially in the adolescents, they not only had to change their parenting style, their responsibilities pertaining to parenting had also increased. For instance, they now had to keep an eye on the children regarding their outdoor activities as well, with no moral support either. Parenting stress also involved being concerned about the children's education. Mothers felt that the children were not only at a loss of privileges and opportunities, their academic performance also suffered in the father's absence. In an earlier study done on adolescents whose fathers were deployed/ posted in field areas, adolescents felt that their studies/ academic performance suffered when their father is away for a field posting (Misra and Singh, 2014). A number of studies have shown that various aspects of parenting can be a source of significant stress to the non-military spouse. Chandra et al., (2008) in their study, found that parenting alone was one of the biggest deployment-related challenge reported by spouses. In a recent survey of at-home parents with deployed partners, the most commonly endorsed stressors were increased parenting responsibilities (83\%) and the need to support a child in dealing with the separation from the deployed parent (80\%) (Chandra et al 2010). New research also indicates that as deployment continues, there is a decrease in "health promotion behaviours" (Padden, Connors \& Agazio, 2011) for home-front parents, reflecting increasing exhaustion as the separation wears on. Through interviews with National Guard/Reservist spouses, Lapp and colleagues (2010) identified that lack of respite was the primary stressor during deployment. Specifically, at-home parents identified "going it alone" and "pulling double duty" as both mom and dad until and often beyond the service member's return as major stressors (Lapp et al 2010).

As women narrated their personal experiences of deployment, they talked about further challenges in addition to the stress of separation, hassles related to management of household affairs and single parenting. Research has shown that the presence of a pile-up of stressors become compounded in their intensity due to the absence of the service member from the family. Military wives expressed several housing related problems in the interviews. The problem of living in rented accommodations was of particular concern to them as it affected their children. They talked of high rent, lack of facilities, playground etc. for children, lack of security and burden of being alone. Their major concern centred on the well-being of their children within the indifferent and often selfish civil environment. Prolonged care giving to 


\section{Exploring the Challenges Faced By Indian Military Wives during Spousal Deployment/ Field Area Posting}

an ailing family member like parents or in-laws or one's own children, death of a family member, one's own ill health and pregnancy were some of the other stressful events, wives reported. Deployment of to a Highly active field area or to a high-altitude terrain, were events which raised concerns about the safety and security of the military spouse. Inability to communicate and leave related problems were other stressors commonly discussed by the wives. Family disputes added to the woes of the wives during deployment. The patriarchal family system continues to determine the life of the Indian military wife across ranks even during deployment. Husband being the head of the family decides whether the wife and children will go back to stay with the in-law's family or they will stay in Field Area Family Accommodations provided by the military. Whatever the choice, wives reported having been at the receiving end of in-law's angst. They felt that they were not treated properly by the inlaws in the absence of the husband and staying away from them resulted in tussle over sharing/remitting of a part of the husband's salary to them. As mentioned earlier, it becomes a complex situation for a military family where the soldier has not only to look after his wife and children but also provide for parents and siblings.

Despite the stressors most military families are able to survive the challenges and grow into resilient families. Padden et al. (2011b) analyzed the relationship between "stress, coping, general well-being" in a sample of 105 female spouses of currently deployed service members, and found that army wives who had experienced previous deployments utilized confrontive coping. Confrontive coping means they were able to face a situation and problem solve effectively to deal with the stress (Padden et al., 2011b). Keeping busy, engaging in self care and health oriented activities, seeking support, and positive self-talk were the strategies women reported as helpful in getting through deployment in this study. These strategies were used to distract them from the stress and worry of deployment, help them attain resources, get assistance, and positively reframe their situations. These are useful in decreasing their personal demands (e.g., negative emotions, increased responsibilities) and enhancing personal gains (e.g., self-enhancement, positive affect). Staying busy, seems to be what helps the spouse most through the time of separation from their deployed spouse. "Self-distraction" was ranked fifth on a list of coping strategies most commonly used by civilian wives (Dimiceli et al., 2010). The distraction strategies that spouses indicate are keeping busy by focusing on the kids, or by immersing themselves into work around the house or their job (Wheeler \& Stone, 2010; Lapp et al., 2010).

Self-care and engaging in health-oriented behaviour, making prudent choices about whom to interact with and how best to utilize their time was another coping strategy reported the participants in this study. Research has shown that at-home spouses utilize self-care activities as a coping strategy and the activities tend to vary individually (Wheeler \& Stone, 2010; Lapp et al., 2010). Self-care activities that are utilized include sleep, writing in a journal, and listening to music (Wheeler \& Stone, 2010; Lapp et al., 2010). Similarly, positive affirmations as a coping strategy found in this study, served the purpose of turning the negative emotions into positive and at times of, diluting the negative effects of deployment stressors.

Wives also relied on their religious and spiritual beliefs and practices for coping with stress. Prayers, seeking assurance from god and the notion of 'bhaagya' or destiny helped women stay strong and buffer the stress of deployment. Researchers note that maintaining their spiritual beliefs is a coping strategy military wives use to get through the deployment process (Wheeler \& Stone, 2010). The use of religion as a coping mechanism during deployments

(c) The International Journal of Indian Psychology, ISSN 2348-5396 (e)| ISSN: 2349-3429 (p) | 401 


\section{Exploring the Challenges Faced By Indian Military Wives during Spousal Deployment/ Field Area Posting}

was found to be particularly advantageous to wives who were prepared for the possibilities that their husbands might not return, and who were struggling with the demands of being both mother and father (McCubbin, et al., 1976). Seeking support and assistance from relatives and friends was another coping strategy found in this study which is in consonance with other studies. Lapp et al., (2010) in his study observed that during the deployment period, civilian spouses often seek support from relatives and social relationships.

\section{Implications}

Given the fact that prolonged and multiple deployments have been and are likely to continue to be a reality for the Indian military, addressing the challenges and concerns of at-home family members during deployment and identifying their coping resources will help in understanding and offering interventions and support to the families. It may also be helpful for military service members as they return home to their families and continue in their military positions in peace stations. How the families have coped and steered through the separation period is likely to impact family functioning on the soldiers' return. Furthermore, family adjustment can have an impact on the military's retention of soldiers and soldier effectiveness (Nice, 1981; Pincus et al., 2001). Deployment period functioning within the family is also likely to be related to positive family outcomes post-deployment (Pittman et al., 2004). Thus, working with families during the early stages of deployment might positively influence the well-being of military families, which may in turn improve the health of military personnel (through improved effectiveness) and the military itself (through retention of employees).

Besides exploring the challenges and coping methods employed by Indian military wives during deployment induced separation, this research, offers valuable insights for further research. Interviewing wives of various ranks also meant differences in age, duration of marriage, number of prior field area postings and also their level of education. With a larger sample the impact of these characteristics on experience of various stressors can be further analyzed.

\section{REFERENCES}

B.(2012). A mixed-method approach to understanding the experiences of non-deployed military caregivers. Maternal and Child Health Journal, 16, 374-384. doi:10.1007/s10995-0110772-2

Beard, B., Mathewson, J., Saari, T., \& Campagna, H. (2008). Military children and grief. In K. J. Doka \& A. S. Tucci (Eds.), Living with grief: Children and adolescents (pp. 193-212). Washington, DC: Hospice Foundation of America

Black, W. (1993). Military-induced family separation; A stress reduction intervention. Social Work, 38, 273-280.

Castaneda LW, Harrell MC, Varda DM, Hall KC, Beckett MK, Stern S.(2008). Deployment experiences of Guard and Reserve families. Santa Monica, CA: RAND.

Chandra A, Burns RM, Tanielian TL, et al. (2008). Understanding the impact of deployment on children and families: findings from a pilot study of Operation Purple Camp participants. Santa Monica, CA: RAND.

Dimiceli, E. E., Steinhardt, M. A., \& Smith, S. E. (2010). Stressful experiences, coping strategies, and predictors of health-related outcomes among wives of military servicemen. Armed Forces \& Society, 36(2), 351-373. doi: 10.1177/009532X0932476 5

Holmes, T. H., \& Rahe, R. H. (1967). The social readjustment rating scale. Journal of psychosomatic research, 11, 213. 


\section{Exploring the Challenges Faced By Indian Military Wives during Spousal Deployment/ Field Area Posting}

Jensen PS, Martin D, Watanabe H. (1996). Children's response to parental separation during operation desert storm. J Am Acad Child Adolesc Psychiatry 35(4):433-441.

Lapp, C.A., Taft, L.B., Tollefson, T., Hoepner, A., Moore, K. \& Divyak, K. (2010). Stress and coping on the home front: Guard and reserve spouses searching for a new normal. Journal of Family Nursing, 16, $45-67$.

Lara-Cinisomo, S., Chandra, A., Burns, R. M., Jaycox, L. H., Tanielian, T., Ruder, T., \& Han,

Lazarus, R.S., \& Folkman, S. (1984). Stress, Appraisal, and Coping. Springer: New York.

McCubbin, H.I., Dahl, B.s. (1976). "Prolonged family separation in the military: A longitudinal study," In H.1. McCubbin, B.B. Dahl, and E.J. Hunter (Eds.), Families in the military system (pp. 112-144). Beverly Hills: Sage Publications, Inc.

Misra, P. \& Singh, V. (2014). Exploring the Impact of Parental Military Deployment/Field Posting on Adolescents in Indian Military Families. Psychological Studies, 59 (1), 36 43.

Nice, D.S. (1981). A Longitudinal Analysis of Navy Family Separation. (Technical report) San Diego, CA: Naval Personnel Research and Development Center.

Padden DL, Connors RA, Agazio JG. (2011). Stress, coping, and well-being in military spouses during deployment separation. Western Journal of Nursing Research;33(2):247-267. doi: $10.1177 / 0193945910371319$.

Patton, M. Q. (2002). Qualitative Research and Evaluation Methods (3rd ed.). Thousand Oaks, CA: Sage.

Peebles-Kleiger, M.J. \& Kleiger, J.H. (1994). Reintegration stress for Desert Storm families:

Pincus S.H., House R., Christenson J., Adler L.E. (2001). The emotional cycle of deployment: a military family perspective. US Army Med Dep J. Apr-Jun;:615-623.

Pittman, J.F., Kerpelman, J.L., \& McFadyen, J.M. (2004). Internal and external adaptation in Army families: Lessons from Operations Desert Shield and Desert Storm. Family Relations. 53(3), 249-260.

Strauss, A. and Corbin J. (1990). Basics of Qualitative Research: Grounded Theory Procedures and Techniques. Newbury Park, CA: Sage Publications.

Strauss, A.(1987) Qualitative Analysis for Social Scientists. Cambridge: Cambridge University Press.

Warner, C.H., Appenzeller, G.N., Warner, C.M., and Geiger, T. (2009). Psychological effects of deployment on military families. Psychiatric Annals. 39(2), 56-63.

Wartime deployments and family trauma. Journal of Traumatic Stress, 7(2), 173-194.

Wheeler, A.R. \& Torres Stone, R.A. (2010). Exploring stress and coping strategies among National Guard spouses during times of deployment: A research note. Armed Forces \& Society. 36(3), 545-557.

\section{Acknowledgements}

The author appreciates all those who participated in the study and helped to facilitate the research process.

\section{Conflict of Interest}

The author declared no conflict of interests.

How to cite this article: P Misra (2019). Exploring the Challenges Faced By Indian Military Wives during Spousal Deployment/ Field Area Posting. International Journal of Indian Psychology, 7(3), 387-403. DIP:18.01.045/20190703, DOI:10.25215/0703.045 